\title{
A Colorimetric Assay for Chemical Heparin in Plasma
}

\author{
Michael D. Klein, ${ }^{*}$ Robert A. Drongowski, ${ }^{*}$ Robert J. Linhardt, $\dagger$ AND \\ ROBERT S. LANGER $\dagger$
}

\begin{abstract}
*Section of Pediatric Surgery, Department of Surgery, University of Michigan, Ann Arbor, Michigan 48109; and †Department of Nutrition and Food Science, Massachusetts Institute of Technology, Cambridge, Massachusetts 02139
\end{abstract}

Received January 12, 1982

\begin{abstract}
A simple, rapid colorimetric assay for plasma heparin is presented. The assay employs the metachromasia of azure A when heparin is added. It is useful for 0 to 10 units $/ \mathrm{ml}$ and does not depend on heparin's anticoagulant activity. Heparin concentrations determined with this assay are not exactly the same as those determined with coagulation assays. This is probably because azure $A$ determines chemical heparin, not anticoagulant active heparin.
\end{abstract}

Heparin assays in clinical use have been based on heparin's biological activity as an anticoagulant. These range from the simple whole-blood clotting time to the measurement of the accelerating effect of trace amounts of heparin on the neutralization of activated Factor $\mathrm{X}$ by its plasma inhibitor (1). Using the biological coagulation system as an amplifier has permitted the determination of very low levels of heparin $(0.01$ to 1 unit $/ \mathrm{ml}$ ). Doses of heparin much lower than those causing anticoagulation will release lipoprotein lipases from endothelium, adipose tissue, and liver resulting in dramatic clearance of serum triglycerides (2). This lipolytic activity, however, has not been adapted for the assay of heparin. Assays for chemical heparin have been performed by titrating plasma with protamine or polybrene and using a coagulation assay as an end point (3). The direct chemical assay of heparin has been limited to solutions not containing protein. Dietrich determined heparin degradation products by their absorption at $232 \mathrm{~nm}$ after treatment with heparinase (4). Scott described the determination of 2-amino sugars after treatment of heparin with nitric acid (5). Colorimetric reactions with various dyes have also been used in non- protein-containing solutions for determination of heparin without prior degradation (6). The azure A assay has been proposed as a method for standardization of heparin units (7). Jaques has studied the metachromatic reaction of heparin with azure $A$ and toluidine blue most extensively (8). When determining plasma heparin, however, he employs an extraction process first (9). Estes has stated that the metachromatic assays are not suitable for plasma heparin determination (10), mainly due to the interference of proteins and relatively high ionic strength.

We have used the azure A assay effectively in crude bacterial cell sonicates to follow heparinase production by Flavobacterium heparinum (11). This encouraged us to investigate its application in plasma heparin determinations.

\section{MATERIALS AND METHODS}

Azure A, certified biological stain, was obtained from Fisher Scientific Company. Ten grams is dissolved in $100 \mathrm{ml}$ distilled water and gravity-filtered through Whatman No. 5 filter paper. This concentrated solution is stored at $4^{\circ} \mathrm{C}$ for up to 2 weeks. The concentrated solution is diluted by adding $1 \mathrm{ml}$ 

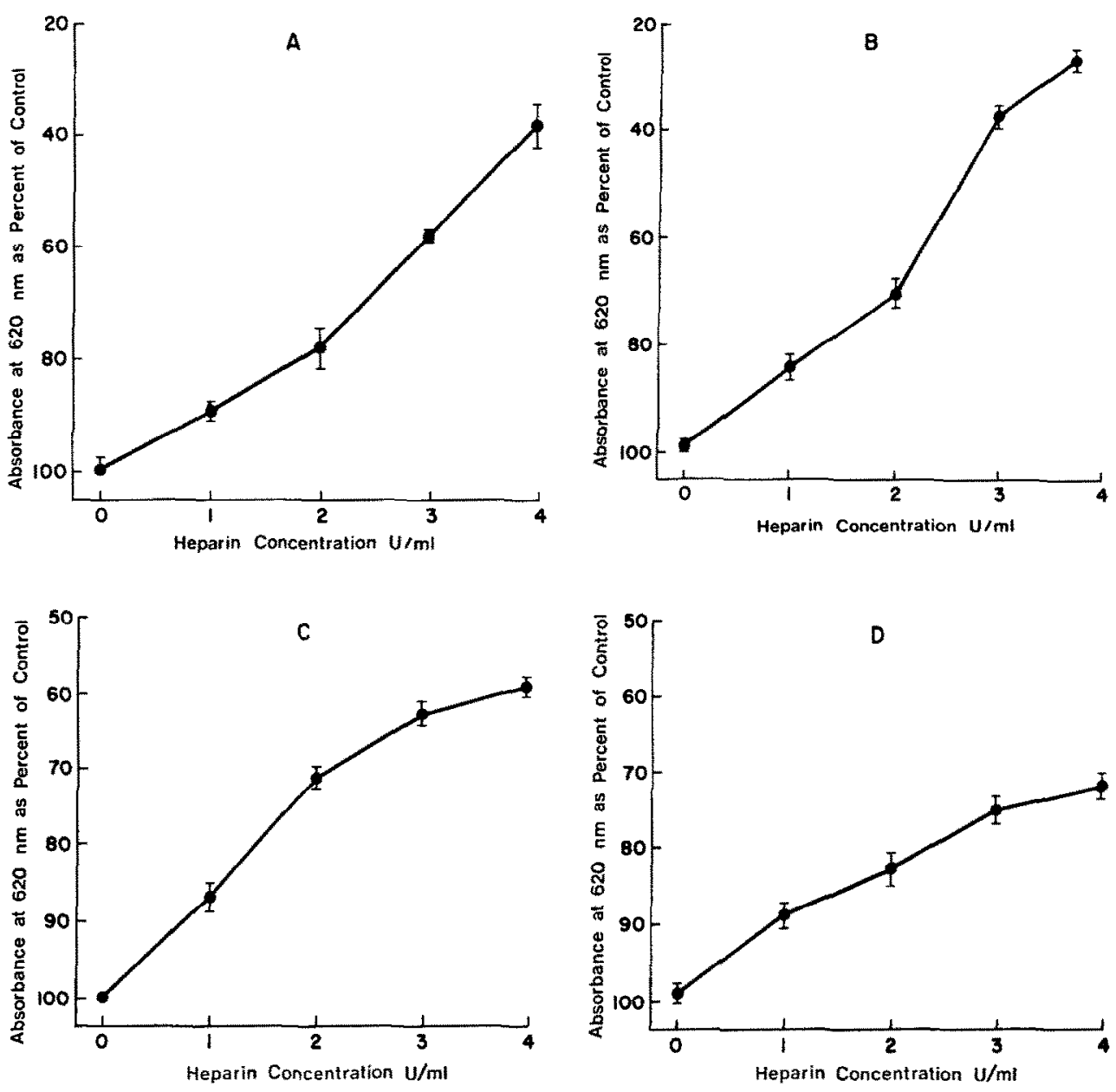

Fig. 1. Standard curves using the 4-unit azure $A$ assay. Five aliquots were assayed from each sample prepared by adding a known amount of commercial heparin to the medium in vitro. Limits represent \pm 1 SD. (A) BLH in NS. (B) BLH in $5 \%$ BSA in NS. (C) BLH in rabbit plasma. (D) BLH in human plasma.

to $11.5 \mathrm{ml}$ of distilled water resulting in an azure A concentration of $8 \mathrm{mg} / 100 \mathrm{ml}$. To perform an assay in the heparin range 0 to 4 units $/ \mathrm{ml}$ (the 4-unit assay), $1 \mathrm{ml}$ of azure A solution $8 \mathrm{mg} / 100 \mathrm{ml}$ is added to $1 \mathrm{ml}$ of sample and vortex mixed. This is then read immediately at $620 \mathrm{~nm}$ in a Bausch \& Lomb Spectronic 88 spectrophotometer. The disappearance of a chromophore is followed so the blank or control consists of the solution (usually plasma) without heparin and the spectrophotometer is set at 1.8 .
For an assay with a greater range although less discrimination (the 10-unit assay), concentrated azure A solution is diluted $1 \mathrm{ml}$ in $99 \mathrm{ml}$ of distilled water to yield an azure $A$ solution of $1 \mathrm{mg} / 100 \mathrm{ml}$. To perform this assay, $100 \mu$ lof sample is added to $2 \mathrm{ml}$ of the azure A solution $1 \mathrm{mg} / 100$ $\mathrm{ml}$. This is then vortex mixed and read at $620 \mathrm{~nm}$ as in the 4-unit assay.

Wherever feasible, plastic laboratory utensils are used. Glassware is cleaned scrupulously with chromic acid solution by soak- 
ing overnight and then washing with water and acetone. The glassware is then siliconized using Prosil-28, PCR Research Chemicals, Inc., Gainesville, Florida.

Beef lung heparin $(\mathrm{BLH})^{1}$ was heparin sodium injection USP (beef lung) obtained from the Upjohn Company, Kalamazoo, Michigan, Lot $801 \mathrm{HY}$. Porcine mucosal heparin (PMH) was heparin sodium injection USP (porcine intestinal mucosa) from Organon Inc., West Orange, New Jersey, Lot $2381811 \mathrm{~B}$ (Liquaemin sodium). Bovine serum albumin (BSA), Fraction V was obtained from Sigma Chemical Company, St. Louis, Missouri. Clinical grade $0.9 \%$ sodium chloride injection, USP was used for normal saline (NS) from Abbott Laboratories, North Chicago, Illinois.

The activated partial thromboplastin time (APTT) was determined using the Platelin Activator Assay Kit from General Diagnostics, Morris Plains, New Jersey. Results are reported as the natural log of the APTT in seconds since this represents a more linear relationship between heparin concentration and the APTT (12).

Human plasma was obtained from an informed donor using $3.8 \mathrm{~g} / 100 \mathrm{ml}$ sodium citrate $1: 10$ as an anticoagulant and centrifugation at $2000 \mathrm{rpm}, 4^{\circ} \mathrm{C}$ for $15 \mathrm{~min}$.

New Zealand White rabbits weighing approximately $2 \mathrm{~kg}$ were anesthetized for the animal experiments with rompun, $0.45 \mathrm{mg} /$ $\mathrm{kg}$, subcutaneously, and ketamine, $0.45 \mathrm{mg} /$ $\mathrm{kg}$, intramuscularly. Blood was obtained by catheterization of the right atrium via the right external jugular vein and then diluted $10: 1$ with $3.8 \mathrm{~g} / 100 \mathrm{ml}$ sodium citrate. Plasma was obtained by centrifugation at $2000 \mathrm{rpm}, 4^{\circ} \mathrm{C}$, for $15 \mathrm{~min}$. In the in vivo experiments, anesthesia was maintained and the catheter was left indwelling in the right atrium for drug administration and blood

\footnotetext{
${ }^{1}$ Abbreviations used: BLH, beef lung heparin; PMH, porcine mucosal heparin; BSA, bovine serum albumin; NS, normal saline; APTT, activated partial thromboplastin time.
}

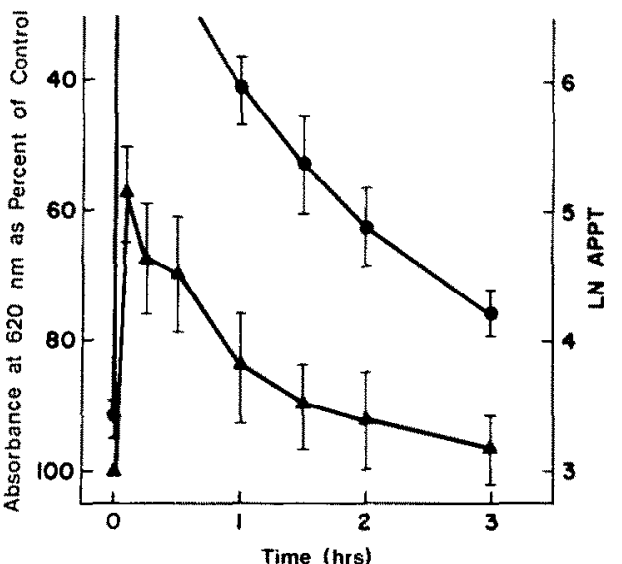

FIG. 2. In vivo appearance and disappearance of BLH in rabbits. Six rabbits were given 400 units $/ \mathrm{kg}$ of BLH intravenously at $1 \mathrm{~min}$. Limits represent $\pm 1 \mathrm{SD}$. Azure A assay (triangles) and In APTT (circles) were followed.

sampling. An initial blood sample was taken, heparin administered, and then blood samples again taken at timed intervals.

\section{RESULTS}

Standard curves were prepared with BLH in NS, 5\% BSA in NS, rabbit plasma, and human plasma. Five aliquots from each tube were determined using the 4-unit assay (Fig. 1). Student's $t$ test shows that the differences between each point are significant with $P$ values less than 0.05 . In a similar experiment assaying known concentrations of heparin every $0.5 \mathrm{unit} / \mathrm{ml}$ for a range 0 to 4 units/ $\mathrm{ml}$, the difference between each $0.5 \mathrm{unit} / \mathrm{ml}$ was always significant with $P<0.05$. In in vivo experiments, 400 units $/ \mathrm{kg}$ of BLH was administered to six different rabbits and blood samples obtained for determination of the APTT and heparin by azure A assay. These results are presented in Fig. 2. Further in vivo experiments are shown in Fig. 3. In separate groups of at least three animals each, either BLH or PMH in doses of 200 and 400 units $/ \mathrm{kg}$ was administered intravenously. Venous blood was sampled at intervals for $3 \mathrm{~h}$. A standard curve employing $\mathrm{BLH}$ in rabbit plasma using the 10 -unit as- 


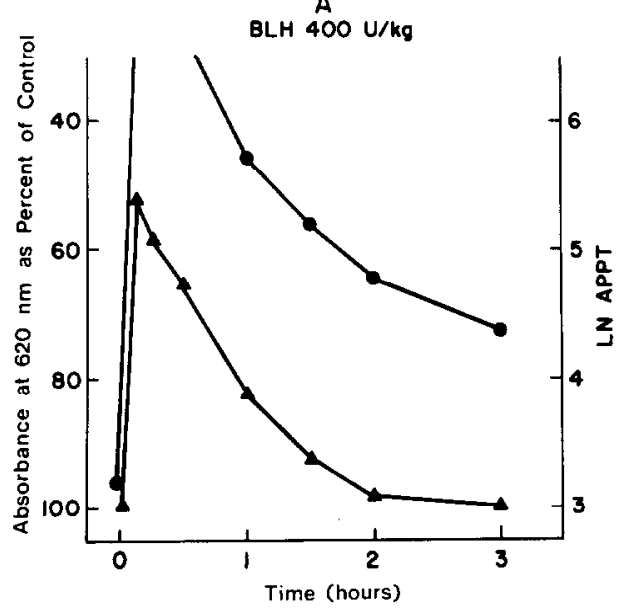

C

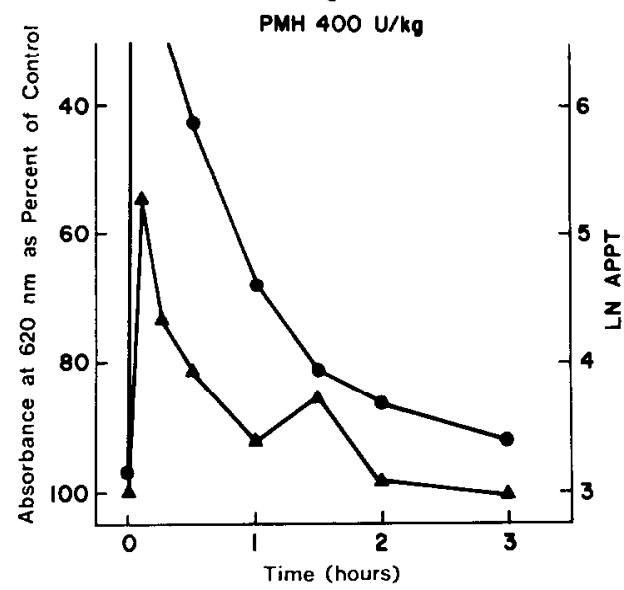

B

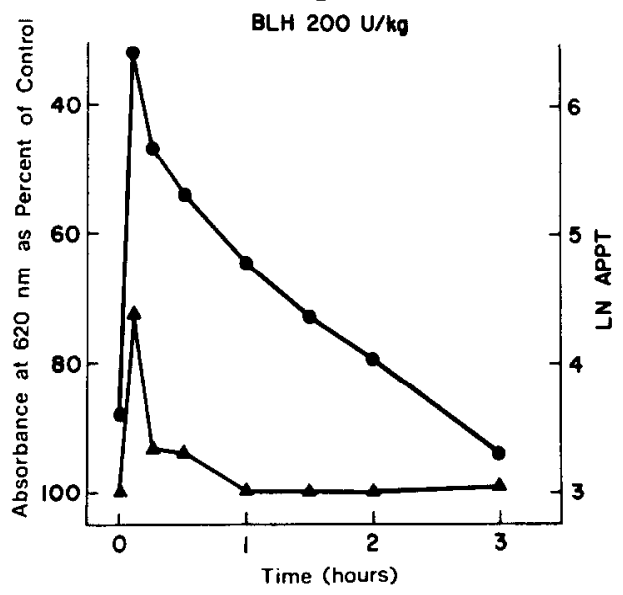

D

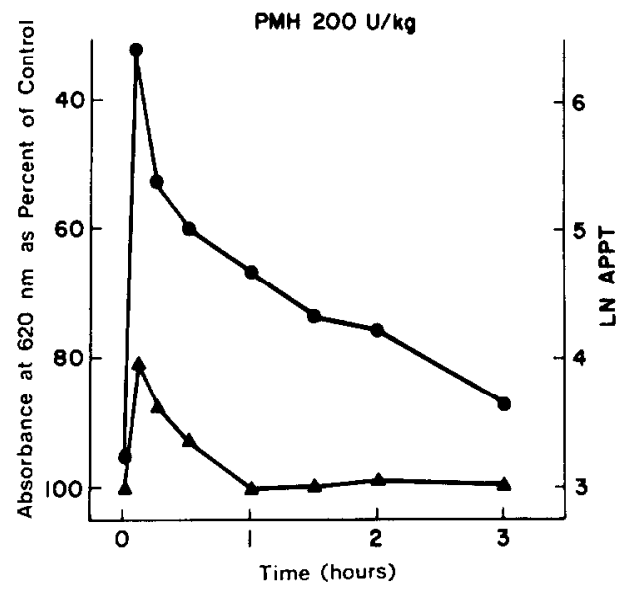

Fig. 3. In vivo appearance and disappearance of heparin from two sources at two different doses in rabbits. Each curve demonstrates one representative animal. Azure A assay (triangles) and In APTT (circles) were followed. Heparin was given intravenously at $1 \mathrm{~min}$. (A) BLH, $400 \mathrm{units} / \mathrm{kg}$. (B) BLH, 200 units/kg. (C) PMH, 400 units $/ \mathrm{kg}$. (D) PMH, 200 units $/ \mathrm{kg}$.

say is illustrated in Fig. 4. Student's $t$ test shows significant differences ( $P$ less than 0.05 ) between every 2 units of heparin.

\section{DISCUSSION}

Many investigators using azure $A$ to measure heparin used concentrations of azure A of $10 \mathrm{mg} / 100 \mathrm{ml}$ and more $(6,7,9,13)$. By using a lower concentration, we obtained less variation in absorbance of the blanks. Other investigators have also examined primarily the change in absorption at $520 \mathrm{~nm}$ although the disappearance of absorption at $620 \mathrm{~nm}$ has been noted (13). While following absorbance at $520 \mathrm{~nm}$ gave excellent results with heparin in NS and heparin in 5\% BSA in NS, both our in vivo and in vitro assays were not reproducible if we used $520 \mathrm{~nm}$. Attempts to improve the assay with various buffers were futile.

The standard curves in Fig. 1 demonstrate the 4-unit assay's reproducibility in ionic strength of $0.154(\mathrm{~A})$, in a simple protein solution (B), and in complex plasma systems (C and D). Figure 2 demonstrates the re- 
producibility of this assay in vivo. The standard deviations are wide, but so are the standard deviations for the APTT. These variations may relate to biological variability in the in vivo distribution of heparin between various body compartments (14), but might be due to in vivo interconversion of heparin between active and inactive configurations (15). The in vivo experiments in Fig. 3 demonstrate the assay's effectiveness for both PMH and BLH at two different doses.

The mechanism of the metachromatic reaction of dyes with heparin has been discussed most fully by Jaques (14). Resonance in the dye molecules allows a partial charge to form on each end of the dimer of the dye. This permits loose interaction with the negatively charged heparin molecule, and thus blocks the amino groups on the dye reducing $\pi$-electron delocalization. With less electron mobility the dye molecule absorbs light energy at a shorter wavelength. The same shift can occur with a high salt concentration with no heparin and the dye-polyanion complexes show a critical electrolyte concentration effect. This may explain why buffering negatively affects the assay.

Since the azure A assay performs well in NS and in 5\% BSA in NS, a part of the coagulation system is not involved in the reaction. The assay appears to be a direct chemical assay which can determine heparin both free and protein bound in plasma.

The difference in the heparin disappearance curves followed by APTT and azure A in the in vivo experiments is interesting. While the curves are similar, azure A shows earlier return of heparin levels toward baseline. This indicates that the azure $A$ assay is measuring something different from the APTT; perhaps heparin amount and not heparin effect. It might also mean that a particular biologically active form of heparin, perhaps that bound to antithrombin III, is not determined by the azure A assay. Or it may be, as suggested by Levy and Jaques (16), that heparin is converted in vivo to a more active form. Heparin molecules may

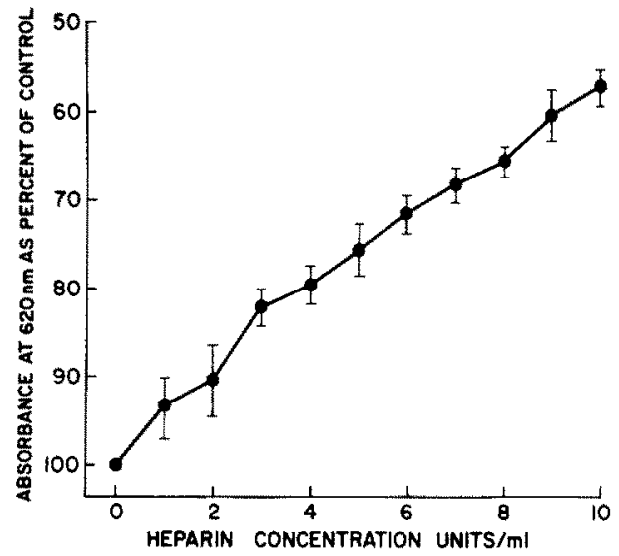

FIo. 4. Standard curve using the 10-unit azure $A$ assay. Five aliquots were assayed from each sample prepared by adding a known amount of commercial BLH to rabbit plasma in vitro. Limits represent $\pm 1 \mathrm{SD}$.

be in a particularly inactive configuration in vitro as determined by the manufacturer, and are then converted in vivo to an active configuration. Heparin itself might cause a change in the proteins of the coagulation system which persists after the heparin has disappeared. Investigation of these hypotheses could provide some answers to questions concerning the fate of intravenous heparin.

The azure A assay's advantages over other chemical assays are its simplicity and rapidity. Its advantage over coagulation assays in clinical use is its ability to rapidly determine high concentrations of heparin.

\section{ACKNOWLEDGMENTS}

We thank Susan Johnston, Diana Hill, Steven Hoffberg, Gerald Fitzgerald, and Arnold Coran, M.D., for their contributions to this work, and Richard Levenson, M.D., for introducing us to Analytical Biochemistry. This project was supported by BRSG SO7 RR05383 awarded by the Biomedical Research Support Grant Program, Division of Research Resources, National Institutes of Health, and by National Institutes of Health Grant GM25810.

\section{REFERENCES}

1. Yin, E. T., Wessler, S., and Butler, J. V. (1973) J. Lab. Clin. Med. 8, 293-310.

2. Asmal, A. C., Leary, W. P., Thandroyen, F., Botha, 
J., and Wattrus, S. (1979) Brit. J. Clin. Pharmacol. 7, 531-533.

3. Godal, H. C. (1960) Scand. J. Clin. Lab. Invest. 12, 446-457.

4. Dietrich, C. P. (1968) Biochem. J. 103, 647-654.

5. Scott, J. E. (1979) Biochem. J. 183, 91-97.

6. Anderson, W., Harthill, J. E., and Pryce-Jones, R. H. (1979) J. Pharm. Pharmacol. 31(Suppl.), $93 \mathbf{P .}$

7. Copley, A. L., and Whitney, D. V., III (1943) $J$. Lab. Clin. Med. 28, 762-769.

8. Jaques, L. B. (1977) Methods Biochem. Anal. 24, 203-312.

9. Jaques, L. B., Monkhouse, F. C., and Stewart, M. (1949) J. Physiol. (Iondon) 109, 41-48.
10. Estes, J. W. (1980) Clin. Pharmacokinet. 5, 204 220.

11. Galliher, P. M., Cooney, C. L., Langer, R., and Lindhardt, R. J. (1981) Appl. Environ. Microbiol. 41, 360-365.

12. Bjornsson, T. D., and Wolfram, K. M. (1981) Ann. N. Y. Acad. Sci. 370, 656-661.

13. Jaques, L. B., and Bell, H. J. (1959) Methods Biochem. Anal. 7, 253-309.

14. Jaques, L. B. (1980) Pharmacol. Rev. 31, 99-166.

15. Bjornsson, T. D., Wolfram, K. M., and Kitchell, B. B. (1982) Clin. Pharmacol. Ther. 31, 104113.

16. Levy, S. W., and Jaques, L. B. (1978) Thromb. Res. 13, 429-441. 